UDC:159.922.76-056.26: $364.65[364.444: 340.6+364-786]$ DOI: 10.26697/ijes.2019.2.29

\section{Main Psychological Factors of Life Perspective Formation in the Context of Medical-Social Expertise and Rehabilitation for Young People with the Status of Disabled Child}

Senior Researcher Honchar Yu. A. ${ }^{1}$

${ }^{1}$ State Institution "Ukrainian State Institute of Medical and Social Problems of Disability, Health Ministry of Ukraine", Ukraine

\begin{abstract}
Background:

In the research "To develop approaches to medical and social expertise and rehabilitation of young people with a status of a disabled child on the basis of their life perspective assessment", one of the aspects touched on social implementation and the availability of a focus on education and work for young people with the status of a disabled child at different ages. It was proposed a model for assessing the life perspective of young people which had the status of a disabled child.

Forming state social policy in relation to people with disabilities many countries put the priority importance to the social approach, promoting their wider involvement in public life, realization of their citizens' rights and affecting the content of measures aimed at reducing negative consequences of disability. Modern approaches consider disability as a limitation of life activities, based on the "International Classification of Functioning, Disability and Health", which includes various spheres of the individual functioning in society. Participation in public life is of great importance for the health and well-being of young people with disabilities and their families.

The purpose of the study: the definition of the leading medical, social and psychological factors that lead to the disability of young people.

Life perspective is the individual's management of the time of his own life, where the ways of life goals realization in society are an important factor in organizing activity in the future. The basis for building a life perspective is a personality goal, built plans and value orientations, programmed and expected events.
\end{abstract}

\footnotetext{
Methods:

Open controlled study covered 140 young people with a status of a disabled child. The criteria for inclusion in the study were: age 18-29 years, a disabled child status. Patients were divided into groups: the first group included boys and girls aged 18 to 22 , the second group - young people aged 23 to 29 years.
}

\section{Results:}

We proposed a model for assessing the life perspective of young people which had the status of a disabled child based on the theory of Erickson (Psychosocial development of the person), the model of Orum (three systems of development of an adult person) and allocated by Hylko, parameters of age as a basis and the results of development, which also included the definition of the dynamic structure of "Me" as a personality, "Me" as a member of the family, "Me" as an employee and the vector of implementation in the context of society and culture (Drozdova, Khramtsova, Honchar, 2017).

Personal social implementation was investigated according to the following parameters: education, employment and labor orientation. Among all surveyed, in terms of education, the indicators were distributed as follows: secondary special education $46.8 \%$, higher $-29.8 \%$, secondary education $-17.0 \%$ and incomplete secondary education $-6.4 \%$. Most of them were those who studied $(34.0 \%)$ and worked $(25.5 \%)$, and the less was the number of those who studied and worked (4.5\%) or did not have any employment $(36.2 \%)$. Labor orientation was more evident in the desire to work $(31.9 \%)$ and at the same time to study and work (31.9\%); only $21,3 \%$ of people wanted to study and the lack of labor orientation characterized $14.9 \%$ of young people.

\section{Conclusions:}

The focus of the life perspective of the individual forms in childhood, so the study of socio-psychological factors, both normal and impaired development, should be investigated at every age stage in order to prevent or correct adverse changes in a timely manner.

\section{Information about the author:}

Honchar Yulia Akeksandrovna - Doctor of Philosophy in Medical Psychology, Senior Researcher, Head of Psycho-Neurology, Psychotherapy and Medical Psychology Scientific Group, Department of Medical and Social Expertise and Rehabilitation of Internal, Nervous Diseases and Psychosomatic Disorders, State Institution "Ukrainian State Institute of Medical and Social Problems of Disability, Health Ministry of Ukraine"; Associate Professor of Psychology and Special Education Department, School of General Psychology and Abnormal Psychology, Oles' Honchar Dnipro National University, Dnipro, Ukraine.

Research interests: medical and social expertise, psychological correction; http://orcid.org/0000-00015316-906X.

Corresponding Author:

Honchar Yulia Akeksandrovna

Corresponding Author's Email:

Gonchar.yulia@gmail.com 